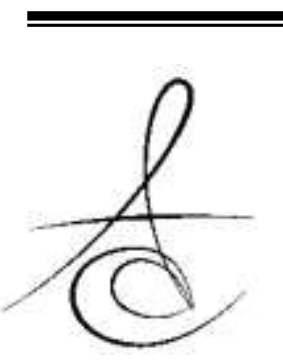

\title{
PERİODONTİTÍS HİKAYESİ PERİ-İMPLANTİTİS GELİşİMİ AÇISINDAN BİR RİSK FAKTÖRÜ MÜDÜR ? 3 YIL TAKİPLI OLGU SUNUMU
}

\author{
IS PERIODONTITIS HISTORY A HIGHER RISK FOR PERI-IMPLANTITIS \\ PROGRESSION ? A CASE REPORT WITH 3 YEARS FOLLOW-UP
}

\section{Dt. Ezgi Sıla TAŞKALDIRAN*}

\author{
Prof. Dr. Gülay TÜTER*
}

\author{
Makale Kodu/Article code: 4009 \\ Makale Gönderilme tarihi: 06.03 .2019 \\ Kabul Tarihi; 10.10 .2019
}

Ezgi Sıla Taşkaldıran: ORCID ID: 0000-0001-7580-4263

DOI : $10.17567 /$ ataunidfd.631781

Behruz Aliyev: ORCID ID: 0000-0002-9479-1936

Gülay Tüter: ORCID ID: 0000-0002-4264-0829

\section{ÖZ}

Amaç: Periodontitis kaynaklı diş kaybı olan ve mevcut implantlarında peri-implantitis gelişen olgunun, cerrahi tedavi aşamaları ve 3 yıllık takip sürecinin sunulması amaçlanmıştır.

Olgu: Sistemik olarak sağlıklı ve sigara kullanmayan 43 yaşındaki kadın hasta kliniğimize peri-implant bölgede ağrı ve ciddi kanama şikayetiyle başvurdu. Hastanın dişlerini periodontal nedenlerle kaybettiği ve sonrasında dental implantların yapıldığı; mandibuler implantların 6 yıl içerisinde kaybedildiği öğrenildi. Klinik muayenede 7 peri-implant bölgede yumuşak dokuda ödem, $\geq 10 \mathrm{~mm}$ sondlama derinliği ve sondlamada kanama bulundu. Radyografik incelemede ise ileri düzeyde peri-implant kemik kaybı saptandı. Tüm değerlendirmeler sonucunda 7 adet implantın çıkarılmasına karar verildi. Operasyonlara hazırlık aşamasında implant üzeri sabit protezlerin sökümü planlandı ve bu sırada 3 implant kaybedildi. İlk operasyonda, 13-14 bölgesindeki implantlar çıkarılarak bölgeye rejeneratif tedavi uygulandı. Takip eden operasyonda, 23-27 bölgesindeki implantlar çıkarıldı. Bu operasyon sırasında molar bölgede maksiller sinüs membranının, alveoler kret üzerinde ağız içine açık olduğu görüldü. Bu bölge kolajen membranla kapatılıp, tüm bölgelere rejeneratif tedavi uygulandı. Üçüncü operasyonda, sağ molar bölgedeki implant çevresi tam kalınlık flep kaldırılarak, peri-implantitis tedavisi uygulandı.

Sonuç: Periodontitis hikayesi olan hasta, 2008-2016 yılları arasında 13 implantını kaybetti. Bu da, periodontitis hikayesine sahip bireylerin, peri-implantitis açısından artmış risk altında olduğu fikrini desteklemektedir.

Anahtar kelimeler: periodontitis, peri-implantitis, dental implantlar.

\section{ABSTRACT}

Aim: The aim of this case report is to present the surgical treatment stages and 3 years follow-up period of a case who has peri-implantitis lesions and tooth loss due to periodontitis history.

Case: 43-year-old woman who was systemically healthy and non-smoker, referred to our department with peri-implant problems. It was learned that she had lost her teeth because of the periodontal reasons, then dental implants had been placed and then she lost mandibular implants in 6 years. In the clinical examination, peri-implant soft tissue edema and $\geq 10 \mathrm{~mm}$ probing depth measurements with bleeding on probing were observed. Advanced peri-implant bone loss was detected on radiographs. After the examination, removal of implants was decided. In the curse of removal of fixed denture, 3 implants were lost. Firstly, implants 13-14 were extracted and regenerative treatment was performed. Later, implants 23-27 were extracted. In molar region, it was observed that maxillary sinus membrane was exposed to the oral cavity on the alveolar crest. This site was covered with resorbable collagen membrane; regenerative treatment was performed in all regions. Finally, peri-implantitis treatment was performed on implant 16.

Result: The patient with a history of periodontitis lost 13 implants between 2008-2016. This supports the idea that individuals with a history of periodontitis are at greater risk for peri-implantitis.

Key Words : periodontitis, peri-implantitis, dental implants.

\section{* Gazi Üniversitesi Diș Hekimliği Fakültesi, Periodontoloji Anabilim Dalı, Ankara}

Kaynakça Bilgisi: Taşkaldıran ES, Aliyev B, Tüter G. Periodontitis Hikayesi Peri-İmplantitis Geliş̧imi Açısından Bir Risk Faktörü Müdür ? 3 Yıl Takipli Olgu Sunumu. Atatürk Üniv Diş Hek Fak Derg 2020; 30: 290-294.

Citation Information: Taskaldiran ES, Aliyev B, Tuter G. Is Periodontitis History a Higher Risk For Peri-Implantitis Progression ? A Case Report With 3 Years Follow-Up. J Dent Fac Atatürk Uni 2020; 30: 290-294. 


\section{GİRİş}

Günümüzde dental implant destekli protezler, geleneksel sabit veya parsiyel protezlere göre daha fazla tercih edilmektedir. İmplant sayılarının artışıyla birlikte dental implantlar çevresinde oluşan sorunlar da artmaktadır. ${ }^{1}$ Literatürde implant kayıplarına, periodontal hastalıklar, sistemik hastalıklar ve sigara kullanımı gibi faktörlerin yol açtığı belirtilmektedir. Nitekim bu faktörlerden biri olan periodontitis hikayesi, periimplantitis gelişimi açısından risk faktörü olarak oldukça fazla düzeyde karşımıza çıkmaktadır. ${ }^{2}$ Bir meta analizde, periodontitis hikayesine sahip bireylerde, sağlıklı bireylere kıyasla, ileri dönemlerde artmış sondlama derinliği ve kemik kaybına rastlandığı ve bu bireylerin daha yüksek oranda peri-implantitis gelişme riski olduğu belirtilmiştir. ${ }^{3}$ Literatür incelemesinde keratinize dişeti miktarı ile peri-implantitis gelişme sıklığı arasındaki ilişki ile ilgili ise net sonuçlara rastlanamamıştır. ${ }^{4}$ $\mathrm{Bu}$ makalede, periodontitis hikayesine bağlı diş kaybı olan olan ve çok sayıda implantını peri-implantitis nedeniyle kaybeden bir olgunun tedavisi ve 3 yıllık takip sürecinin detaylı olarak sunulması amaçlanmıştır.

\section{OLGU SUNUMU}

43 yaşında, sistemik olarak sağlıklı, sigara içmeyen ve laktasyon döneminde olan kadın hasta 2015 yılında Gazi Üniversitesi Diş Hekimliği Fakültesi Periodontoloji Anabilim Dalı Kliniği'ne implantların çevresinde ağrı ve ciddi kanama şikayeti nedeniyle başvurdu. Hastanın anamnezinden 2007 yılında periodontal sorunlar nedeniyle dişlerini kaybettiği, 1 yıl sonra dental implant operasyonlarının özel bir klinikte yapıldığı (6 mandibula, 8 maksilla) ve mandibuler implantların 2 yıl aralıklarla kaybedildiği; hastaya bu dönemde arayüz temizliğini içeren ek bir oral hijyen önerisinin verilmediği öğrenildi. Hastanın dişlerini kaybetme sebebinin, yaşı ve aile hikayesi gibi faktörler dikkate alınarak agresif periodontitise bağlı olduğu kanısına varıldı. 2017 Dünya Çalıştayı'nda belirlenen güncel sınıflama dikkate alındığında ise hastanın dişlerini kaybetme aşamasında şiddetine göre Evre 4, yayılım hızına göre Derece $C$ ve yayılım kapsamına göre yaygın periodontitise sahip olduğu düşünüldü. ${ }^{5}$ Klinik muayenede, 7 implantın çevresinde yumuşak dokuda ödem, $\geq 10 \mathrm{~mm}$ sondlama derinliği ve sondlamada kanama saptandı $(13,14,17,21,23,25,27)$ (Resim 1a). Diğer implant çevresinde (16) ise ortalama $2 \mathrm{~mm}$ sondlama derinliği ve sondlamada kanama gözlendi. Alınan panoramik ve periapikal radyografilerde peri-implant bölgelerde ciddi seviyede kemik kaybı saptandı (Resim 1b). Tüm incelemeler sonucunda 7 adet implantın şiddetli peri-implantitis nedeniyle çıkarılmasına karar verildi. Hasta tedavi planıyla ilgili bilgilendirildi ve hastadan onam alındı. Tedavi aşamasında implant üzeri sabit protezlerin sökümü planlandı ve üst yapıların sökülmesi esnasında 3 implant $(17,21$ ve 25$)$ kaybedildi.
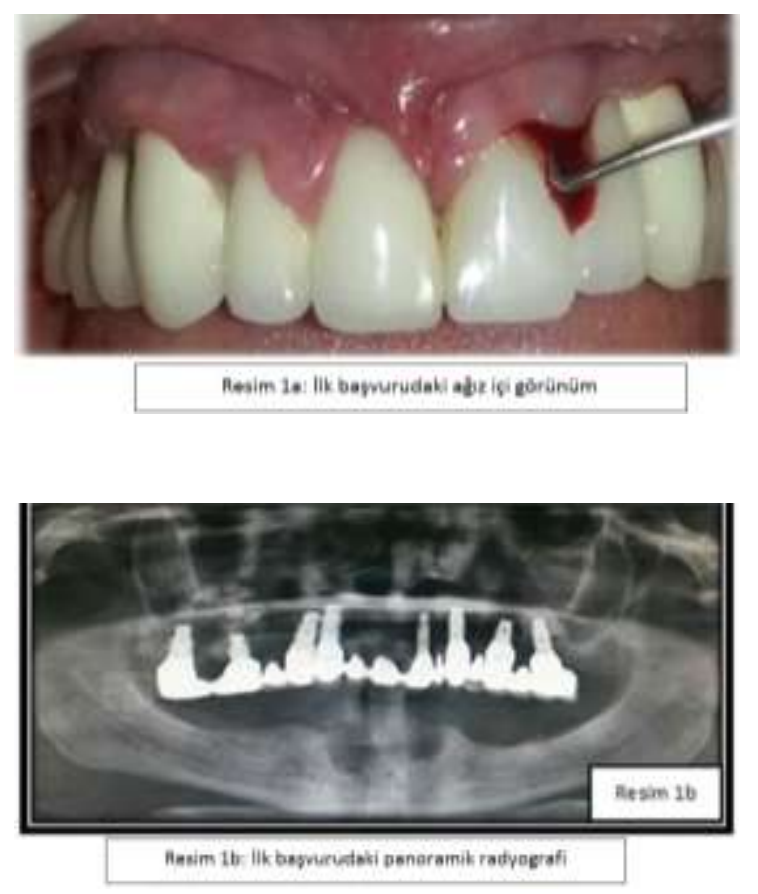

İlk operasyonda, 13 ve 14 bölgesindeki implantlar çıkarılarak, rahatlatıcı insizyonlarla desteklenen operasyon bölgesine greft materyali $(0,5$ Bio-oss small, Geistlich) ve 3 tabaka şeklinde konsantre büyüme faktörü (KBF) membranı uygulandı ve flep primer olarak sütüre edildi (Resim 2). Sonraki operasyonda, 23 ve 27 bölgesindeki implantlar çıkarıldı. Operasyon sırasında 23 bölgesinde yoğun kemik kaybının olduğu ve 26 bölgesinde maksiller sinüs membranının oral kaviteye açık olduğu görüldü (Resim 3). Sinüs membranının oral kaviteye açık olduğu bölge, rezorbe olabilen bir kolajen membranla çift kat olarak (Memlok $15 \times 20 \mathrm{~mm}$ kolajen membran, Bio Horizons) kapatılarak tüm bölgelerde greft materyali (Cerabone $1 \mathrm{gr}$, Botis) ve üzerine KBF birkaç kat membran olarak uygulandı. Böylece hasta toplam 7 implantını kaybetmiş oldu. Üçüncü operasyonda ise, 16 bölgesindeki implant çevresi tam kalınlık flep kaldırılarak, implant 
yüzeyi titanyum küretlerle temizlenerek peri-implantitis tedavisi uygulandı.

Operasyonlar sonrasında hastaya geçici hareketli protez planlaması yapıldı. Mandibuler protezin stabilizasyonu ve mukoza irritasyonu oluşturmaması açısından mandibuler kret yüzeyi düzeltildi. Greft materyali (1 gr Bio-oss small, Geistlich) ve otojen kemik grefti kullanılarak bölge tek kat kolajen membranla (Bio-Gide 30x40 mm kolajen membran, Geistlich) kapatıldı ve membran fiksasyon vidalarıla sabitlendi.

Tüm planlanan operasyonlardan önce hastaya antibiyotik (Augmentin BID $1 \mathrm{gr}, 2 \times 1,10$ gün), anti enflamatuar ilaç (Majezik 100 mg, 2x1, 5 gün) ve ağız çalkalama solüsyonu (Kloroben gargara, 2x1, 12 gün ve Gengigel, $2 \times 1,1$ ay) reçete edildi. Operasyonların tamamlanmasının ardından hastanın isteğiyle alt ve üst hareketli tam protez planlanarak hastaya tam protezler yapıldı. Hasta halen 3 yıllık takip periyodunda ve kontrolümüz altındadır (Resim 4a-b).
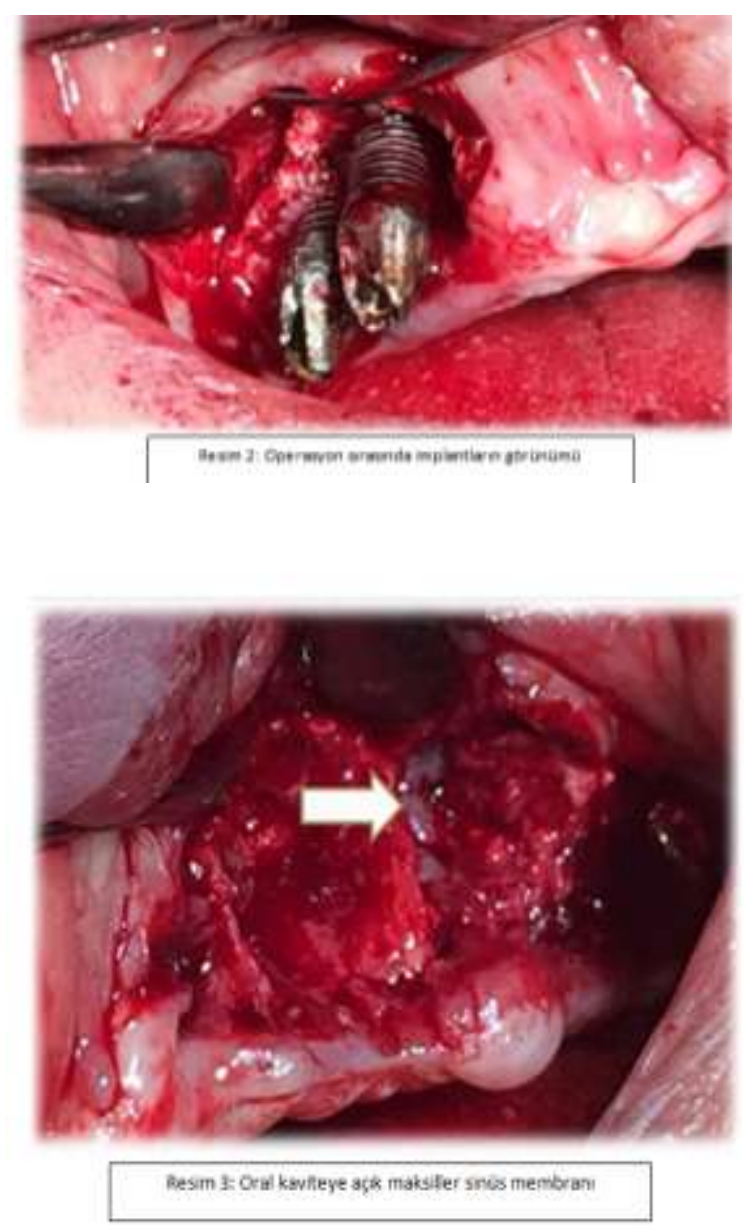

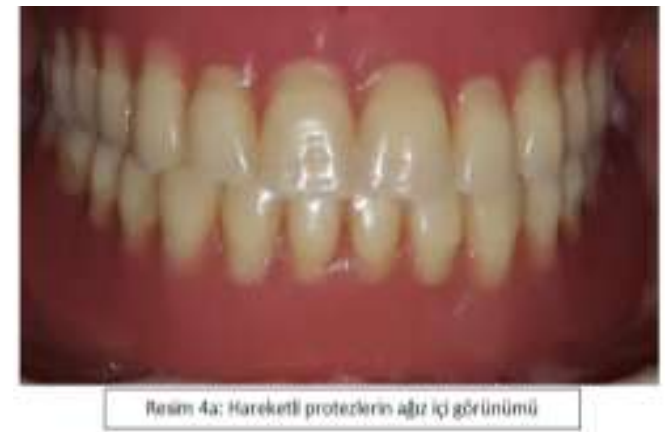

\section{TARTIŞMA}

Yapılan araştırmalarda, implant uygulanacak bireylerdeki periodontal hastalık öyküsünün periimplant hastalık riskini 2 kat arttırdığı bildirilmiştir. ${ }^{6}$ Bir çalışmada periodontitis hikayesi olan ve periodontal olarak sağlıkı bireylerde uygulanan dental implantlar çevresindeki kemik kaybı miktarı değerlendirilmiştir. Çalışma sonuçlarında, periodontitis hikayesi olan bireylerde uygulanan dental implantlar çevresinde kemik kaybı miktarının 5 yıl sonra $2.6 \mathrm{~mm}$, periodontal olarak sağlıklı bireylerde uygulanan dental implantlar çevresindeki kemik kaybı miktarının ise $1.2 \mathrm{~mm}$ olarak tespit edildiği rapor edilmiştir. ${ }^{2}$ Bir başka çalışmada periodontal olarak sağlıklı ve periodontal hastalıklı bireylere dental implantlar uygulanmış ve hastalar 10 yıl boyunca takip edilmiştir. Çalışma sonuçlarına göre dental implantlar çevresinde $5 \mathrm{~mm}$ ve üzeri cep derinliğinin görülme oranı periodontal olarak sağlıklı bireylerde $\% 2$, orta derecede periodontal hastalıklı bireylerde \%16 ve şiddetli derecede periodontal hastalığa sahip bireylerde \%27 olarak bulunmuştur. ${ }^{7}$ Benzer şekilde başka bir çalışmada, periodontitis nedeniyle tedavi gören hastalarda daha fazla peri-implant komplikasyonu ve implant kaybı yaşanabileceği bildirilmiştir. $^{8}$ 3-16 yıllık takipli bir çalışmada, implant sağkalım oranı, yaygın agresif periodontitis hikayesine sahip bireylerde \%96, sağlıklı grupta \%100 olarak bulunmuştur. Çalışmada sonuç olarak agresif periodontitis hikayesine sahip bireylerde peri-implant mukozitis görülme sıklığı sağlıklı gruba göre 3 kat, peri-implantitis görülme oranı 14 kat, implant başarısızlık oranı ise 5 kat daha fazla olarak bildirilmiştir. ${ }^{9} \mathrm{Bu}$ verilere bakılarak, periodontitise bağlı diş kaybının, periimplantitis insidansını ve peri-implant marjinal kemik kaybını önemli ölçüde arttırdığı söylenebilir. Bu bilgilerle uyumlu olarak çalışmamızda sunulan hastada mevcut periodontitis hikayesinin, bu kadar kısa sürede ve çok sayıda implant kaybını etkilemiş olabileceğini

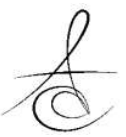


düşünmekteyiz. Nitekim sunulan vakaya ait anamnez ve geçmiş dönem radyografileri, hastada şiddetli agresif periodontitis varlığına bağlı diş kayıpları yaşandığını göstermektedir.

Literatürde, artık cepler, periodontal idame tedavisine dahil olmamak ve sigara kullanımının uzun dönem implant başarısını olumsuz yönde etkilediği bildirilmiştir. ${ }^{10,11}$ Nitekim sunulan vakada hasta implant uygulamaları öncesinde herhangi bir periodontal tedavi görmediğini belirtmiştir. Dolayısıyla mevcut periodontal risk faktörleri varlığında implant cerrahileri uygulanmış ve sonuçta peri-implantitis gelişimi kaçınılmaz olmuştur.

Peri-implant bölgelerin mikrobiyolojik anlamda incelendiği bir çalışmada, periodontitis hikayesi olan bireylerin etkilenmiş peri-implant bölgelerinde periodontal patojen mikroorganizmaların baskın olduğu açıklanmıştır. ${ }^{12}$

Lang ve arkadaşları, peri-implant lezyonları için bir terapötik tedbir protokolü tasarlamıştır. Bu sistem, lezyonun ciddiyetine ve derecesine bağlı olarak artan antibakteriyel potansiyele sahip bir dizi terapötik uygulamayı içermektedir. Bu protokole göre kullanılacak klinik parametreler için şu kriterlerin değerlendirilmesi gerekmektedir: 1) dental plak varlığı veya yokluğu; 2) sondlamada kanama varlığı veya yokluğu 3) süpürasyon varlığı veya yokluğu; 4) peri-implant sondlama derinliği ve 5) radyografik olarak saptanan kemik kaybının varlığı. ${ }^{13}$ Rejeneratif tedavinin ve onarımın mümkün olmayacağı durumlarda ise implantIarın çıkarılması, hastalığın ilerlememesi açısından önerilen bir prosedürdür. ${ }^{14}$ Sunulan olguda da, bahsedilen bu tedavi protokolüne uygun olarak, implantlar çevresinde sondlama derinliği $10 \mathrm{~mm}$ ve üzerinde tespit edilen bölgelerde rezektif cerrahi uygulanarak dental implantlar çıkarılmıştır. 16 no'lu implant bölgesinde ise tam kalınlık flep kaldırılarak implant yüzeyi titanyum küretlerle mekanik olarak temizlenmiştir.

Olgumuzun ilk muayene seansında implantlar çevresinde tespit edilen $\geq 10 \mathrm{~mm}$ sondlama derinliği, yumuşak dokuda ödem, sondlamada kanama ve pü varlığı, radyografik olarak implant boyunun 2/3'ünden fazla kemik kaybı şiddetli peri-implantitis varlığı olarak değerlendirilmiştir. Hastadan alınan sözlü anamnezde implant uygulaması öncesinde periodontitis kaynaklı diş kayıpları dikkati çekmektedir. Literatür bilgileri, periodontitis hikayesi olan bireylerde implant başarısının ve sağ kalımının periodontal açıdan sağlıklı bireylerle kıyaslandığında anlamlı olarak düşük olduğunu ve bu durumun peri-implantitis gelişimi açısından önemli bir risk olarak kabul edilmesi gerektiğini göstermektedir. Nitekim sunulan olgu da literatür bilgilerini desteklemektedir.

Periodontitis hikayesi olan hastalarda takip periyotlarının daha sık oluşturulması ve destekleyici tedavi ile oral hijyen seviyelerinin en üst düzeyde tutulması ile implant başarı oranları yükseltilebilir.

NOT: Calışmada herhangi bir yazar, kurum ya da kuruluş ile çıkar çatışması içerisinde bulunmamaktadır. Makale daha önce hiçbir yerde yayınlanmamış ve yayınlanmak üzere işlem görmemektedir

\section{KAYNAKLAR}

1. Maruyama N, Maruyama F, Takeuchi Y, Aikawa C, Izumi $Y$, Nakagawa I. Intraindividual variation in core microbiota in peri-implantitis and periodontitis. Sci Rep. 2014;4:6602.

2. Gatti C, Gatti F, Chiapasco M, Esposito M. Outcome of dental implants in partially edentulous patients with and without a history of periodontitis: a 5year interim analysis of a cohort study. Eur J Oral Implantol. 2008;1:45-51.

3. Sgolastra F, Petrucci A, Severino M, Gatto R, Monaco A. Periodontitis, implant loss and periimplantitis. A meta-analysis. Clin Oral Implants Res. 2015;26:8-16.

4. Peker E, Karaca İE. İmplant Tedavisinin Prognozunu Etkileyen Lokal Risk Faktörleri. J Dent Fac Atatürk Uni 2015;10:105-11.

5. Caton JG, Armitage G, Berglundh T, Chapple ILC, Jepsen S, Kornman KS, Mealey BL, Papapanou PN, Sanz M, Tonetti MS. A new classification scheme for periodontal and peri-implant diseases and conditions - Introduction and key changes from the 1999 classification. J Periodontol. 2018;1:1-8.

6. Dalago HR, Schuldt Filho G, Rodrigues MA, Renvert $S$, Bianchini MA. Risk indicators for Peri-implantitis. A cross-sectional study with 916 implants. Clin Oral Implants Res 2017;2:144-50.

7. Roccuzzo M, Bonino F, Aglietta M, Dalmasso P. Ten-year results of a three arms prospective cohort study on implants in periodontally compromised patients. Part 2: clinical results. Clin Oral Implants Res 2012;4:389-95.

8. Chrcanovic BR, Albrektsson T, Wennerberg A. Periodontally compromised vs. periodontally healthy patients and dental implants: a systematic review and meta-analysis. J Dent 2014;42:150927. 
TAŞKALDIRAN, ALIYEV, TÜTER

9. Swierkot K, Lottholz P, Flores-de-Jacoby L, Mengel R. Mucositis, peri-implantitis, implant success, and survival of implants in patients with treated generalized aggressive periodontitis: 3- to 16-year results of a prospective long-term cohort study. J Periodontol 2012;83:1213-25.

10. Zangrando MS, Damante CA, Sant'Ana AC, Rubo de Rezende ML, Greghi SL, Chambrone L. Longterm evaluation of periodontal parameters and implant outcomes in periodontally compromised patients: a systematic review. J Periodontol 2015; 86:201-21.

11. Saaby M, Karring E, Schou S, Isidor F. Factors influencing severity of peri-implantitis. Clin Oral Implants Res 2016;27:7-12.

12. Apatzidou D, Lappin DF, Hamilton G, Papadopoulos CA, Konstantinidis A, Riggio MP. Microbiome of peri-implantitis affected and healthy dental sites in patients with a history of chronic periodontitis. Arch Oral Biol 2017;83:145-52.

13. Lang NP, Wilson TG, Corbet EF. Biological complications with dental implants: their prevention, diagnosis and treatment. Clin Oral Implants Res. 2000;11:146-55.

14. Robertson K, Shahbazian T, MacLeod S. Treatment of peri-implantitis and the failing implant. Dent Clin North Am 2015;59:329-43.

\section{Yazışma Adresi}

Prof.Dr.Gülay Tüter

Gazi Üniversitesi Diş Hekimliği Fakültesi

Periodontoloji AD

Emek-Ankara-Türkiye

Telefon: +90 3122034240 - +90 5322262425

e-posta: gulay@gazi.edu.tr 